\section{CELEBRATE SMILE MONTH}

The Dental Directory's oral hygiene range provides free next day delivery. Especially for Smile Month, it has some great offers on all your patients' regular oral hygiene essentials as well as great deals on gift packs, motivational stickers, children's toothpaste and toothbrushes which can be handed out at Smile Month oral hygiene meetings and events as well as to include in goodie bags.

All Smile Month offers can be found inside the latest issue of the Dental Directory's oral hygiene catalogue, Big Bite.

Reader response number 53

\section{UNIQUE PIVOT SYSTEMS}

Design Specific produce a wide range of wheelchair platforms and recliners. The designs are derived totally from the clinical needs of patients and staff. Design Specific wheelchair platforms and recliners optimise the seated position of the clinician and offer the safest working environment.

A low head position is needed for convenient working but this has to be achieved without excessive tilting of the patient. Tilting beyond 45 degrees for most patients is uncomfortable and impossible for many medical conditions.
Design Specific products achieve this with their unique pivot systems. The Full Function Platform can raise and lower the patient, as well as tilt, providing a true dental chair for the disabled patient.

Design Specific services extend beyond just supply of equipment. With ten years of experience behind them the staff have a unique insight into the requirements for disability dentistry. They offer a consultancy service, turnkey clinic design and installation and bespoke product design.

Reader response number 54

\section{IMPROVING THE PATIENT- PRACTICE RELATIONSHIP}

Denticom offers several managed services that are easily incorporated into any dental surgery, improving the patient-practice relationship and client communication. These include Patient Call where you can identify lost revenue by spotting missed calls, and therefore increase your profitability while improving the service you give to your patients.

Patient Point cuts down queue times at the desk with a self 'check-in' point for patients that can be programmed with questionnaires and loaded with practice information. Patient Text sends text messages to patients to remind them of their appointment which can reduce 'no-shows' by up to 50\%.

When a patient calls the practice, Denticom's service displays their name on screen so they can be greeted with a warm and friendly welcome, which will help to strengthen the practicepatient relationship. When the practice's lines are busy, the 'engaged' tone can be replaced by pre-programmed messages promoting the practice's services. Should the patient have to queue to speak to reception, they will be informed of their place in the queue. Reader response number 56

\section{NEW GEL TOOTHPASTE LAUNCHED}

Arm \&t Hammer's Brilliant Sparkle Gel toothpaste can achieve superior plaque removal by actually neutralising its bonds and removing it effectively from tooth surfaces. It contains CrystalClean technology, a unique plaque-dissolving agent, which neu- tralises plaque, breaking its bonds with enamel to dissolve and remove it. As with all Arm \& Hammer products it contains baking soda which neutralise acids and odour. The Enamel Care range uses Liquid Calcium technology to rebuild surface enamel. Arm \&

\section{PROTECTING THE HEALTH OF TEETH}

BioRepair Concentrated Mouthwash is an enamel repair mouthwash which strengthens and protects the health of teeth by repairing the damaged surface of the enamel. It also protects the gums, freshens breath and effectively combats the build up of plaque and tartar by reaching those difficult areas, allowing the antiseptic action to really get to work on the whole mouth.

BioRepair offers an effective solution against acid attack and erosion as the patented scientific formula contains Microrepair microparticles that are made up of carbonate-hydroxyapatite - this is the same chemical substance that makes up tooth enamel and dentine. These microparticles effectively fill in any microscopic cracks or holes, thereby repairing the damaged enamel surface.

\section{Reader response number 55}

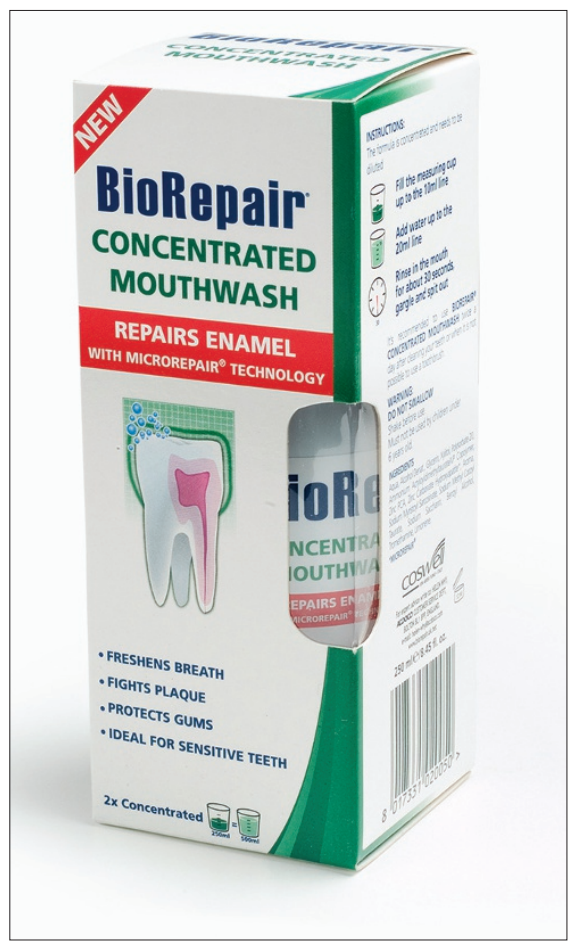

